Ratajczak, J., Marcher, C., Riedl, M., Matt, D.T., Mayer, N., Sánchez, J., Georgiou, G., Rahhal, A., Page, J., Alonso Perez, J.M., Chepegin, V. and Brancart, M. (2017). "Digital Tools for the Construction Site. A Case Study: ACCEPT Project". In: LC3 2017: Volume I - Proceedings of the Joint Conference on Computing in Construction (JC3), July 4-7, 2017, Heraklion, Greece, pp. 981-988. DOI: https://doi.org/10.24928/JC32017/0034.

\title{
DIGITAL TOOLS FOR THE CONSTRUCTION SITE. A CASE STUDY: ACCEPT PROJECT
}

\author{
Julia Ratajczak ${ }^{1}$, Carmen Marcher ${ }^{2}$, Michael Riedl ${ }^{3}$, Dominik T. Matt ${ }^{4}$, Nicolas Mayer $^{5}$, \\ Javier Sánchez ${ }^{6}$, George Georgiou ${ }^{7}$, Anabelle Rahhal ${ }^{8}$, Jason Page ${ }^{9}$, Jesús Miguel Perez \\ Alonso $^{10}$, Vadim Chepegin ${ }^{11}$ and Manon Brancart ${ }^{12}$
}

\begin{abstract}
Construction projects often encounter problems related to scheduling reliability and to a mismatch between the expected and actual building performance. In order to reduce these problems, the ACCEPT project is developing an ICT system to manage construction works more efficiently by applying Lean Construction principles, to increase the quality of executed works by implementing interactive checklists and sensors, and to share information in real-time among different stakeholders. In the ACCEPT system, existing technologies such as Augmented Reality, BIM, mobile/wearable devices and sensors have been combined together to create an innovative ICT solution for construction management. The ACCEPT system consists of three interconnected applications: SiMaApp for mobile devices CoOpApp for smart glasses and Dashboard for PC. The main goal of this research paper is to describe the framework of the ACCEPT system and its applications.
\end{abstract}

Keywords: Digital tools, Augmented Reality, BIM, Lean Construction, Quality Control

\section{INTRODUCTION}

The construction industry (CI) is lagging behind other industries in implementing new Information and Communications Technologies (ICTs) to improve conventional processes and quality of construction works (Brandon et al 2008). In other industries, ICTs have been successfully implemented thanks to several drivers that aim to modernize obsolete approaches and processes. One of these drivers is the $4^{\text {th }}$ industrial revolution, a trend called Industry 4.0. The CI also has to face this challenge in order to keep pace with ongoing transformation at the global level. A legislative driver at European level has

\footnotetext{
1 Research associate, Fraunhofer Italia Research, Bolzano, Italy, and Ph.D. Candidate, Faculty of Science and Technology, Free University of Bozen-Bolzano, Bolzano, Italy, Julia.Ratajczak@natec.unibz.it

2 Research associate, Fraunhofer Italia Research, Bolzano, Italy, carmen.marcher@fraunhofer.it

3 Deputy Director, Michael Riedl, Fraunhofer Italia Research, Bolzano, Italy, michael.riedl@fraunhofer.it

4 Head of Fraunhofer Italia, Fraunhofer Italia Research, Bolzano, Italy, and Full Professor, Faculty of

Science and Technology, Free University of Bozen-Bolzano, Bolzano, Italy, dominik.matt@unibz.it

5 Software Engineer, Ascora GmbH, Bremen, Germany, mayer@ascora.de

Software Engineer, AnswareTech s.l., Madrid, Spain, jsanchez@answare-tech.com

7 Architect, EPITESSERA Architects, Nicosia, Cyprus, georgiou@epitessera.com

8 Architectural Engineer, LUCID-ULg, Faculty of Applied Sciences, University of Liège, Liège, Belgium, anabelle.rahhal@ulg.ac.be

$9 \quad$ Sustainability Specialist, Ingleton Wood LLP, Norwich, UK, jason.page@ingletonwood.co.uk

10 Civil Engineer, Ferrovial Agroman, Madrid, Spain, jmalonso@ferrovial.com

11 Senior Software Engineer, TIE Kinetix, Breukelen, Netherlands, Vadim.Chepegin@TIEKinetix.com

12 Energy and Sustainable Building Engineer, Entreprises Jacques Delens, Brussels, Belgium,

MBrancart@jacquesdelens.be
} 
started to boost the digital revolution to initiate the modernization of the CI. The CI has started to adopt slowly new processes and technologies. In 2014, the European Parliament recommended to modernize the European public procurement law by encouraging the use of computer-based methods such as Building Information Modelling (BIM) for the public founded construction contracts and tendering (EUPPD 2014). According to the European Commission (2016), the industrial revolution is driven by new generation of information technologies such as the Internet of Things, cloud computing, big data and data analytics, robotics and 3D printing. As a result, many companies, such as Autodesk@ and Google $\odot$ are investing in software for cloud-based project coordination, hardware (smart glasses), and mobile applications for Augmented Reality (AR).

In this context, the European Commission funded the ACCEPT (Assistant for Quality Check during Construction Execution Processes for Energy-efficienT buildings) project through the Horizon 2020 Programme. The ACCEPT project is comprised of 11 partners around Europe: Ascora GmbH, AnswareTech s.l., Cype Soft s.l., EPITESSERA Architects, University of Liege - iD's with LUCID-ULg research laboratory, Ingleton Wood LLP, Ferrovial Agroman, TIE Kinetix, Entreprises Jacques Delens s.a., Fraunhofer Italia Research s.c.a.r.l. and Fraunhofer IBP. This project has started in January 2015 and will finish at the end of 2017.

Besides the implementation of promising technologies in the construction site, this project aims to achieve the followings key objectives:

- Knowledge transfer: Improve communication and transfer knowledge between the different stakeholders involved in the construction process by providing construction instructions and information in real-time.

- Project coordination: Increase the efficiency, reliability and productivity of construction processes by providing workflows and monitoring the construction progress based on lean construction principles.

- Quality assurance: Improve the energy and hygrothermal performance of buildings by providing quality assurance tools and self-inspection procedures during the construction process.

In order to reach these key objectives, the project consortium is developing the ACCEPT system with three client applications, which run on wearable devices (smart glasses), mobile devices (tablet and smartphone) and PC. The promising technologies for reforming the $\mathrm{CI}$ such as BIM and AR are also integrated in the ACCEPT system. According to Sacks et al. (2010), 3D and 4D BIM tools enable the visualization of the building product, communicating effectively the design intent. Furthermore, AR has a big potential to be implemented in the CI, since it provides significant advantages at different stages of construction projects through simulation, visualization and interaction. AR allows users to interact with both the real and the virtual objects by overlaying digital information, video, graphics and 3D objects onto real objects (Rankohi and Waugh 2013).

Several ICT platforms for construction management are already available on the market, such as BIM 360॰, Procore $\odot$, Aconex $\odot$, Sablono $\odot$, BIManywhere $\odot$ and Fieldlens $\odot$. Although they are similar to the ACCEPT system, none of those has integrated AR on wearable devices. This lack has provided an opportunity for the ACCEPT project to develop a prototype of the construction management platform, which considers the use of smart glasses. 


\section{SOFTWARE ARCHITECTURE AND DEVELOPMENT}

The ACCEPT system is envisioned as a distributed system with three end user contact points (applications) as well as a contact point for sensors. Figure 1 depicts the high-level architecture of the whole ACCEPT system. The four corners of the architecture are the four interaction points. The interaction with the end users is done via the SiMaApp (mobile device), CoOpApp (smart glasses) and Dashboard (web/desktop). The Sensor Abstraction Framework (SAF) is the interaction point for the sensors/Internet of Things devices. In the centre of the architecture are distributed server applications, which provide the different ACCEPT Services. The Visual Wiki provides assets and information for AR cloud-service in order to interact with Extended Visual Annotations (EVA) and Executed Details Assets (EDA) information. EVA information is a virtual post-it, which can be attached to real world objects. EDA is a complex information such as 3D model, construction drawings, which can be accessed on demand. The Service Market Place (SMP) is the central point for ACCEPT's Open Platform methodology. Further, Knowledge Information Storage (KIS) is a cloud storage, which is used by all components of the distributed system. Finally, the Profile Nexus (PN) provides different services for the interaction with the four profiles: Project Profile, Quality Profile, Workflow Profile and User Profile. It provides the business logic that allows the interaction between profiles in an event-driven environment and it is a kind of Cyber Physical System to have a virtual representation of the different construction sites. In addition, PN exchanges information with BIM software through Data Abstraction Layer (DAL). DAL can also merge metadata of BIM objects with relative construction task created in scheduling software (e.g. Ms Project). Every component communicates through the Autonomous Messaging Framework (AMF).

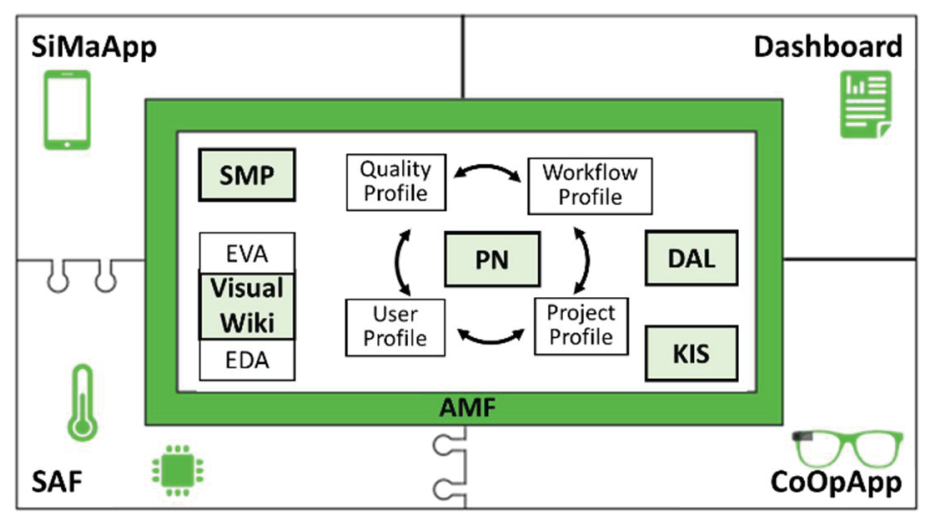

Figure 1: High-level architecture of the ACCEPT system

Software projects always face the communication problem between two distinct groups of stakeholders (e.g., different professional jargons), namely between subject domain experts and software development specialists due to the knowledge and language gap that intrinsically exist. Being fully aware of these problems, the ACCEPT consortium has put in place the best practices that mitigate the risks and increase the chances of the overall success. First of all, the close collaboration and engagement of users have been postulated. In order to overcome the communication gap it has been decided to employ Domain Drive Design (DDD) methodology that provides as-domain ground for building a so-called ubiquities language, i.e. the common language organically developed via cooperation of cross-disciplinary team members. The major outcome of the DDD process is a model expressed in the commonly understood language by team members and used for the communication among specialists of different background. Paper based prototypes 
and mocks greatly helped at the first stages of the project as a mean to develop the common language and the domain understanding. Scenarios have been covered with extensive set of such prototypes and the early test groups of real users were invited to experience them. After that, the software development team has gone into the agile mode of running the software production, using iterative approach and constant communication with the users in order to maximise the business outcomes.

\section{Three Client Applications of THE ACCEPT SYSTEM}

The tangible result of the ACCEPT project is a construction management platform with three interconnected client applications: Site Manager App - SiMaApp, Construction Operator Assistant App - CoOpApp and Dashboard, which run on mobile devices (smartphone and tablet), wearable devices (smart glasses) and PC, respectively.

\subsection{SiMaApp: Application for site managers and foremen}

SiMaApp aims to increase scheduling reliability and productivity of the construction process as well as to support the quality check and reporting procedures on site. It is mainly addressed to site managers and foremen. This application allows users to improve the coordination of construction works and to monitor the construction progress and performance on a daily basis. SiMaApp runs on Android mobile devices. Tablet Project Tango $\odot$ and smartphone Lenovo Phab 2 Pro® have been chosen as test devices. These devices offer many advantages in AR application thanks to integrated sensors, inter alia, motion tracking, depth perception. In SiMaApp users can display information related to project data such as project drawings, construction details, component and material inventory obtained from BIM model. This application is linked to Visual Wiki that enables users to visualize digital information (EVA and EDA), inter alia, 3D models, videos, technical documents and drawings, etc. SiMaApp allows the coordination of the construction process according to Lean Construction principles by implementing approaches of Last Planner System ${ }^{\circledR}$ (LPS) and Location-based Management System (LBMS) (Kenley and Seppänen 2010; Dallasega et al. 2015). SiMaApp provides user with project scheduling, workflows for specific construction tasks and to-do lists to assign commitments to workers. SiMaApp supports also quality control of construction works through standardized checklists that verify delivery status of construction components, installation status of components and construction progress (example in Figure 2b). This application manages resources such as workers, crews and shared equipment involved in the construction project. Furthermore, SiMaApp enables the connection of sensors to collect actively data on the construction site and deliver them to the ACCEPT system.

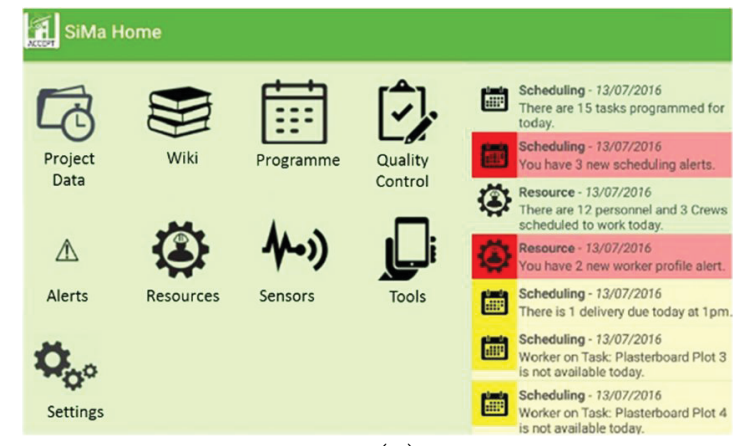

(a)

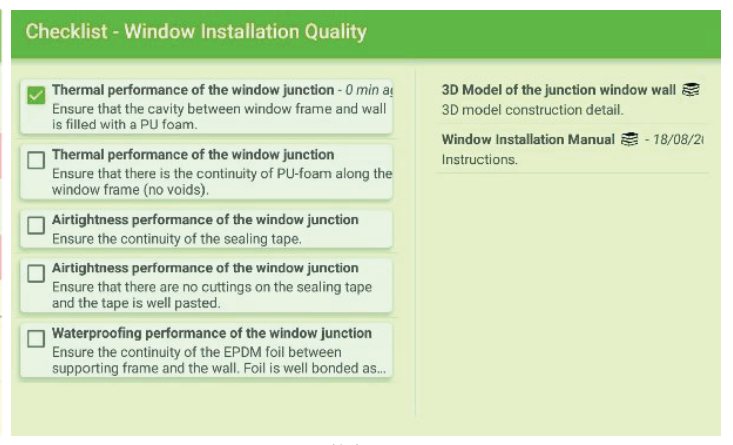

(b)

Figure 2: a) Start page of SiMaApp; b) Checklist to control construction works. 


\subsection{CoOpApp: Application for workers}

CoOpApp is an application running on smart glasses within the ACCEPT ecosystem. It is able to display digital information (from EDA and EVA) in AR (e.g. texts, images, videos or 3D models), take pictures and record video. All these features are available on smart glasses. The application is also compatible with Android devices. CoOpApp is currently used on smart glasses Epson Moverio BT-200@ for three reasons: availability in Europe, price and AR development possibilities. The idea of providing this technology to construction workers stems from the assumption that AR can be a solution for bridging the performance gap between as-planned and as-built, for improving communication between different stakeholders, for sharing documents and for improving the quality control. The use of AR can become essential for control and validation processes on site. Visual Wiki is associated to this application with the ability to link information to real world objects. Pictures, videos, 3D models, technical documents, construction details, drawing or virtual notes can be attached to a specific place (Figure 3). Thanks to this spatial link, a construction worker accesses directly to the right information at the right place. Finally, the application allows a construction worker to share instantly what he sees with his supervisor. Those functionalities are powerful tools to avoid misunderstandings between stakeholders. However, the main problem of smart glasses is related to hardware design, which does not meet Health and Safety (H\&S) standards on construction site. Considering that the use of smart glasses and AR on construction site is not common, special focus groups on construction site with different stakeholders (site manager, workers, etc.) are organized. Focus groups are a valid way to determine strengths and weaknesses of this technology in the context of the construction site and to elaborate H\&S guidelines and recommendations.
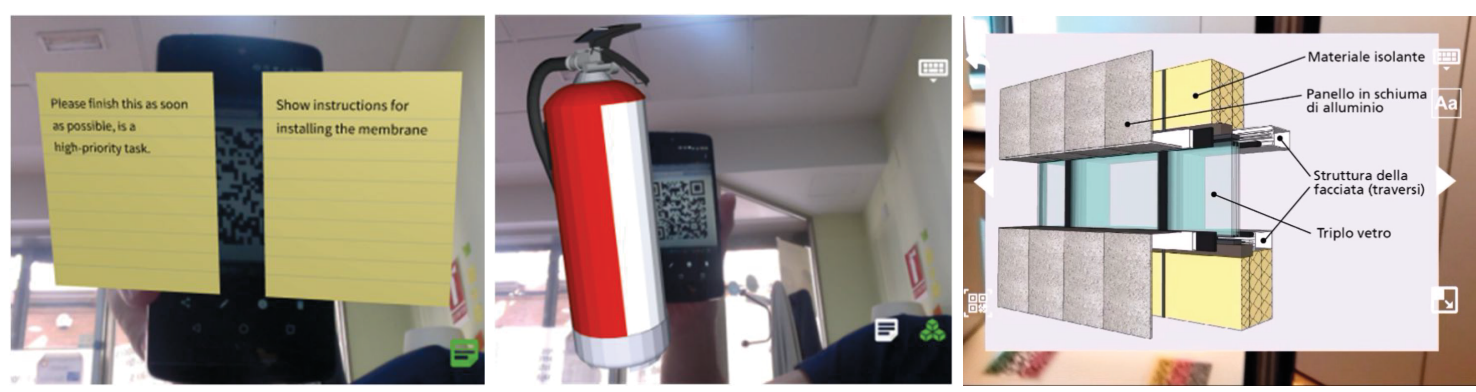

Figure 3: Examples of $C o O p A p p$ features: visualization of virtual note, 3D model, construction details

\subsection{Dashboard: Application to monitor building and construction process quality}

The Dashboard is a web client application developed in DART@ and Polymer@. It uses the responsive design guidelines (Marcotte 2010), which allow web interfaces to adapt to the screen size of its devices. The application is designed mainly for PC but also for tablets and smartphones. Dashboard collects information from multiple sources (sensors, questionnaires and workflows) to synthesize and visualize quality related metrics and issues. In fact, Dashboard communicates with Quality Profile in Profile Nexus to retrieve data from different domains that users want to display. One of the key approaches, while designing Dashboard, was to organize the application in a way to capture the user's attention immediately on data that are more relevant and on problems met during construction. 
According to Fraunhofer IBP (Institut für Bauforschung e. V. 2015) two main factors related to the worsening of the final building quality are always present on construction sites: humidity issues and human errors. In relation to these problems, Dashboard offers two solutions. The first solution is an integration of the communication system between outside and inside sensors to control climate conditions (temperature and humidity), and between manual measurements of surface temperature and humidity of materials, where further construction works should be undertaken (Figure 4a). During the construction, many works can be only done on a dried surface (e.g., screed laying). The site manager can retrieved information from Dashboard about estimated drying time of a material and use it to update properly the work scheduling.

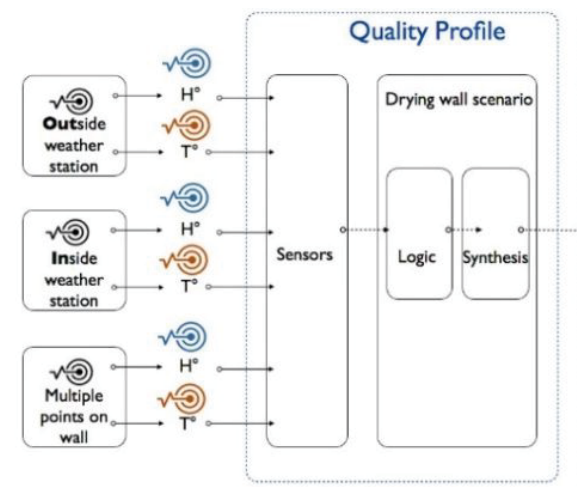

(a)

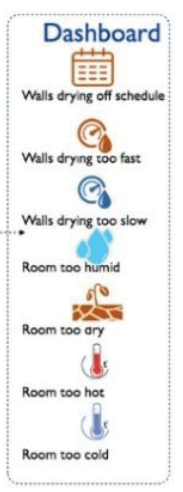

Figure 4: a) Communication schema;

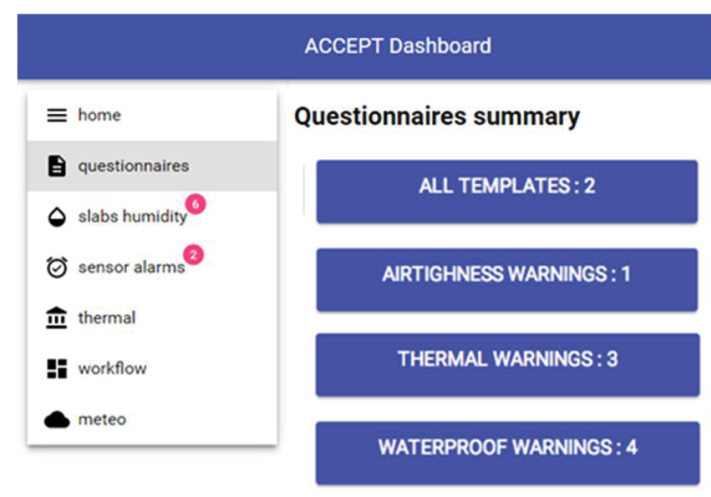

(b)

The second solution is an integration of questionnaires related to specific quality issues (Figure 4b). Information collected by the questionnaires can be used to assist, to document the construction works and to control their quality aspects. In Dashboard can be visualized a list of questionnaire templates and answers as well as groups of warnings generated from the data processing, included in the questionnaire templates.

\section{PiLOT Groups}

All three-client applications will be tested and validated in three Pilot Groups through the Pilot Plans applied to construction sites (pilot projects) in order to measure benefits of technologies used in the ACCEPT system. The Pilot Program is based on the key functionalities derived from the Use Cases, which define what the ACCEPT system aims to achieve. 119 functionalities were identified and collected into 20 groups, which form the basis of Pilot Plans. Figure 5 shows the approach adopted in Pilot Groups. These 20 Pilot Plans fit into three Pilot Groups, which are located in four different European countries. Each Pilot Group is split into two pilot stages. The first pilot stage focuses on qualitative feedback through an iterative process in order to improve the development of the prototype of the ACCEPT system. Validation is achieved through the second pilot stage with advanced prototypes, where qualitative data will be tested against control processes (construction site without the ACCEPT system) in order to prove the concept and quantify the effectiveness and benefits of the ACCEPT system. The second pilot stage is expected to be fulfilled by the end of 2017 . 


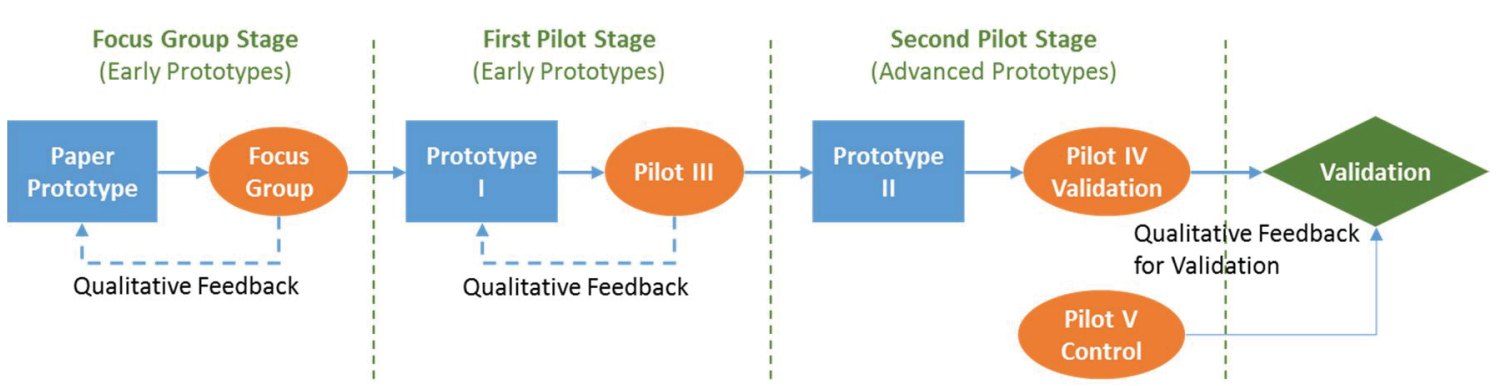

Figure 5: Testing and validation approach adopted in the second Pilot Group.

The first Pilot Group focuses mainly on CoOpApp functionalities. This Pilot Group will be carried out in Madrid and in Brussels and will test usability of smart glasses and functionalities of $C o O p A p p$, inter alia, interactive AR post-its, management of documents in AR, communication between different stakeholders, overlay BIM models in AR with the real world and defect profile to identify a possible mismatch between actual building and as-planned BIM model. Ferrovial Agroman provides the construction site of a residential complex - VIT BOX with 120 apartments in the northern part of Madrid. The second pilot site is located in Brussels and it is a highly energy-efficient project managed by Entreprises Jacques Delens. The second Pilot Group addresses SiMaApp functionalities and it will take place in a rural small residential construction site with a local contractor and with the assistance of a local housing association (Broadland Housing Group). Ingleton Wood will lead the pilot site and will test functionalities related to project coordination, task assignment and crew management with Tablet. The third Pilot Group mainly focuses on Dashboard functionalities and is located in Nicosia, Cyprus. EPITESSERA Architects will carry out this Pilot Group in cooperation with a local contractor during the construction of a school building. Functionalities related to the quality controlling through checklist and sensors, delivery and inventory of materials, interaction with BIM model and usability of Dashboard will be tested in this pilot site.

\section{CONCLUSIONS}

Considering that the $\mathrm{CI}$ is lagging behind other industries in implementing digital technologies, the ACCEPT project aims to boost the implementation of information technologies in the CI. In this project, three applications are developed: SiMaApp CoOpApp and Dashboard. They are mainly addressed to site managers, foremen, and workers and can be used on smart glasses, mobile devices and PC. The original aspects of this project result in the development of an ICT system, which is able to interconnect BIM, AR technologies and sensors in an innovative way to improve the building quality, construction process and real-time knowledge transfer. The prototype of the ACCEPT system is under development and its basic functionalities are currently tested on pilot projects (first stage). In 2017, advanced functionalities of each application will be developed. In SiMaApp, a project scheduling will be implemented according to Lean Construction principles. Features, such as the automated detection of mismatches between BIM model and actual building, will be integrated in CoOpApp. Dashboard will focus on the integration of questionnaires in workflows for construction tasks and on analysing data from sensors. Advanced functionalities will be tested in the second stage of the pilot sites, providing quantitative and qualitative indicators on the use of the ACCEPT system. 


\section{ACKNOWLEDGMENTS}

The authors would like to thank the European Commission for their funding of the ACCEPT project within the Horizon 2020 Framework Programme (Grant Agreement No. 636895). The authors gratefully acknowledge the contributions of the other partners from the consortium: Jesús Martínez and Tonny Velin from AnswareTech; Pablo Gilabert from Cype Soft; Elena Parouti from EPITESSERA Architects; Pierre Leclercq, Hatem Béjar and Vincent Delfosse from LUCID-ULg; Edward Gooden, Greg Day and Kim Kerrigan from Ingleton Wood LLP; Laura Tordera, Olga Gómez and Eduardo Sanz from Ferrovial Agroman; Peter Leo Merz from TIE Germany; Arnaud Dawans from Entreprises Jacques Delens; Christoph Paul Schimanski from Fraunhofer Italia Research; Andreas Kaufmann from Fraunhofer IBP.

\section{REFERENCES}

Brandon, P. S., Kocaturk, T. \& Foundation, R. (2008). Virtual Futures For Design, Construction \& Procurement, Malden, Ma, Blackwell Pub.

Dallasega, P., Rauch E., Matt, D. and Fronk, A. (2015). Increasing productivity in ETO construction projects through a lean methodology for demand predictability. Proceedings of the 2015 International Conference on Industrial Engineering and Operations Management, Dubai, United Arab Emirates (UAE), pp. 1-11.

EUPPD. (January 2014). Directive 2014/24/EU of the European Parliament and of the Council of 26 February 2014 on Public Procurement and Repealing Directive 2004/18/EC.

European Commission. (March 2016). Strategic Policy Forum on Digital Entrepreneurship. Accelerating the digital transformation of European industry and enterprises. Available at: http://ec.europa.eu/DocsRoom/documents/15856/ [Accessed 20 Jan. 2017].

Institut für Bauforschung e. V. (2015). Analyse der Entwicklung der Bauschäden und der Bauschadenkosten. Available at: https://www.bsbev.de/fileadmin/user_upload/Bauherren-

Schutzbund/Aktuell/Studien/15_Forschungsbericht_IFB_Bauschaeden_und_Bauscha denkosten_2015.pdf [Accessed 13 Dec. 2016].

Kenley, R., and Seppänen, O. (2010). Location-Based Management for Construction: Planning, Scheduling and Control. Spon Press, New York, USA.

Marcotte, E. (May 25, 2010). Responsive Web Design. A List Apart. Available at: http://alistapart.com/article/responsive-web-design [Accessed 13 Dec. 2016].

Rankohi, S., and Waugh, L. (2013). Review and analysis of augmented reality literature for construction industry. Vis. in Eng. 1: 9, doi:10.1186/2213-7459-1-9.

Sacks, R., Radosavljevic, M. and Barak, R. (2010). Requirements for building information modeling based lean production management systems for construction. Automation in Construction, 19, pp. 641-655, doi: 10.1016/j.autcon.2010.02.010. 